\title{
Ultra Violet Spectra Studies of Polystyrene Films in Presence of Some Transition Metal Complexes with 4-amino-5-pyridyl)-4h-1,2,4-triazole-3-thiol
}

\author{
RAGHAD HADDAD ${ }^{1}$, EMAD YOUSIF ${ }^{1}$ and RAHIMI M. YUSOP ${ }^{2}$ \\ 'Department of Chemistry, College of Science, Al-Nahrain University, Baghdad, Iraq. \\ ${ }^{2} S c h o o l$ of Chemical Sciences \& Food Technology, Faculty of Science and Technology, \\ Universiti Kebangsaan Malaysia, 43600 Bangi, Selangor, Malaysia.
}

http://dx.doi.org/10.13005/ojc/310175

(Received: November 12, 2014; Accepted: December 04, 2014)

\begin{abstract}
Some coordination complexes of $\mathrm{Ni}(\mathrm{II}), \mathrm{Cu}(\mathrm{II}), \mathrm{Zn}(\mathrm{II}), \mathrm{Cd}(\mathrm{II})$ and $\mathrm{Sn}$ (II) metal with [4amino-5-(pyridyl)-4H-1,2,4-triazole-3-thiol], has been prepared in alcoholic medium and used for photostabilizer for polystyrene. Polystyrene (PS) has been mixed with these complexes in chloroform solvent to form modified PS in (5\%) w/v thickness, which containing concentration of complex 0.5 $\%$ by weight were produced by the casting method from chloroform solvent. The photostabilization of PS films compounds was investigated. The light of the wavelength $365 \mathrm{~nm}$ with intensity $\left(6.02^{*} 10^{-}\right.$ ${ }^{9} \mathrm{Ein} \mathrm{Dm}^{-3} \mathrm{~S}^{-1}$ ) is used for irradiation of PS films at room temperature. The photostabilization activity of these compounds was determined by calculating the photodecomposition rate constant $(\mathrm{Kd})$ for blank and modified polystyrene.
\end{abstract}

Key words: Polystyrene, photodegradation, photostabilization, triazole.

\section{INTRODUCTION}

Triazoles are five memberd heterocyclic compounds containing three nitrogen and two carbon atoms. The substituted triazole with sulphur atom and amine group are considered to be good coordinating ligands because they involved both hard nitrogen and soft sulfur atom as thio amide group, this ligand have doner group that coordinate with wide range of metal ions (Al-Maydama et al. 2008), (Narayana and Gajendragad, 1997). In this paper some complexes of substituted 1,2,4 triazol with thio and amino group has been used as photostabilizer for polystyrene. The low cost and the good performance of PS products have increased the utilization of this polymer in building and other application, it is a multipurpose polymer that is used in varied applications include rigid item. General purpose polystyrene is clear and hard which is used in packaging, laboratory ware, and electronics (Meenakshi et al. 2002). One of the important uses of PS is in the manufacture of cover 
signal lamps of some automobiles (Safy Eldin and El-laithy, 1994), (Yousif et al. 2013 (A)). The photooxidative degradation processes of PS have been discussed in a number of reviews (Rabek and Ranby, 2003), (Lawrence and Weir, 2003). It is generally accepted that carbonyl formed during UV irradiation of polymers, is most probable and are responsible for the yellow coloration of the polymer (Mori et al. 1979). The carbonyl groups generated during the photooxidation process of polymer, extend the polymer film absorption to longer wavelengths. These groups absorb light when they irradiated with light of wavelength between (200$700 \mathrm{~nm}$ ) and activated to the singlet and triplet excited states which enhances various successive photooxidation reactions (Cooray and Scott, 1980). The physical properties of additives and polymers play a very important role in determining the additives efficiency in photostabilization or photodegradation of polymers. For example, the compatibility that any type of additive (photostabilizer, antioxidant, thermal stabilizer.... etc.) must be evenly distributed which requires that it be compatible with the polymer matrix (Gugumus, 1979), (Yousif and Haddad, 2013). In this work the photostabilization of PS was studied by using five complexes of 4-amino-5 (pyridyl)-4H-1,2,4-triazole3-thiol.

\section{EXPERIMENTAL}

\section{Materials}

The following complexes were all prepared by the method described in this reference (Haddad et al., 2013):

These complexes are:

1. Bis(4-amino-5-(pyridyl)-4H-1,2,4-triazole-3-thiol) Nickel(II), Ni(L) $)_{2}$.
2. Bis(4-amino-5-(pyridyl)-4H-1,2,4-triazole-3-thiol) Cupper(II), $\mathrm{Cu}(\mathrm{L})_{2}$.

3. Bis(4-amino-5-(pyridyl)-4H-1,2,4-triazole-3-thiol) Zinc(II), Zn(L) .

4. Bis(4-amino-5-(pyridyl)-4H-1,2,4-triazole-3-thiol) Cadmium(II), $\mathrm{Cd}(\mathrm{L})_{2}$.

5. Bis(4-amino-5-(pyridyl)-4H-1,2,4-triazole-3-thiol) $\operatorname{Tin}(\mathrm{II}), \mathrm{Sn}(\mathrm{L})_{2}$.

The structure of complexes has been shown in figure (1):

\section{Experimental techniques} Films preparation:

A solution of polystyrene $(5 \% \mathrm{w} / \mathrm{v})$ in chloroform was used to prepare $(40 \mu \mathrm{m})$ thickness of polymer films. The films were prepared by evaporation technique at room temperature for 24 hours, to remove the possible residual chloroform solvent. After the evaporation of solvent, that's led to formation of PS films. The thickness of these films is about $401 / 4 \mathrm{~m}$. Modified PS can be prepared by mixing of $0.5 \%$ by weight complexes to the solution containing polystyrene (Yousif et al., 2012), (Yousif et al., $2013(B))$

\section{Irradiation experiments Accelerated Testing Technique:}

UV- Light was used for irradiation of PS films, giving wavelength range between (250 to 380 $\mathrm{nm}$ ) and the maximum wavelength light intensity is

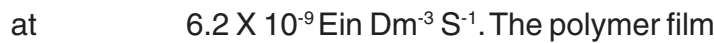
samples were fixed parallel to each other and the lamp of the UV. incident radiation is vertically incident on the samples. The distance between the polymer films and the source was $(10 \mathrm{~cm})$. (Yousif et al., 2011).

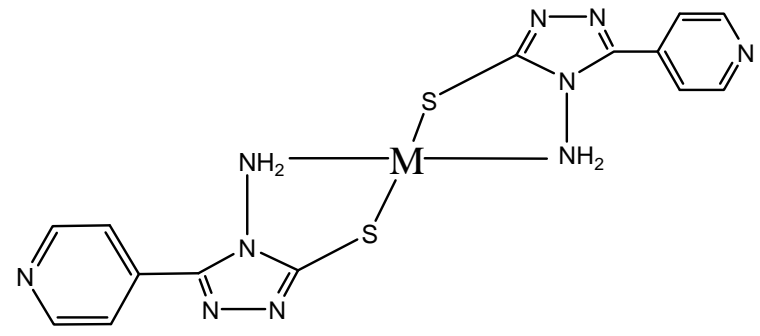

Where M= Ni (II), Cu (II), Zn(II), Cd(II), Sn(II).

Fig. 1: The proposed structure of Complexes 


\section{Photodegradation measuring methods}

Measuring the photodegradation rate of

PS films by using ultraviolet-visible spectrophotometer:

The ultraviolet-visible spectrophotometer type Shimadzu UV-VIS. 160 was used to measure the changes in the Uv-visible spectrum during irradiation time for each compound at maximum absorption band $\left(I_{\max }\right)$. The absorption spectrum was measured in the range of $(200-400 \mathrm{~nm})$, and the $\left(I_{\max }\right)$ at each absorption was also recorded for different irradiation times.

The infinite irradiation time was considered and the infinite absorption $\left(A_{*}\right)$ was assumed to be after the infinite irradiation time.
To determine the photodegradation rate constant for photostabilizer $\left(K_{d}\right)$, the first order equation was used:

$$
\ln (a-x)=\ln a-K_{d} t
$$

Where $a$, represent the stabilizer concentration before irradiation, $x$ represents the change in stabilizer concentration after irradiation time (t).

If $A_{0}$ represents the absorption intensity of the polymer film containing stabilizer before irradiation, $A_{t}$ represents the absorption intensity after $t$ time of irradiation, then:

$$
\begin{aligned}
& a=A_{o}-A_{¥} \\
& x=A_{o}-A_{t} \\
& a-x=A_{o}-A_{¥}-A_{o}+A_{t}=A_{t}-A_{¥}
\end{aligned}
$$

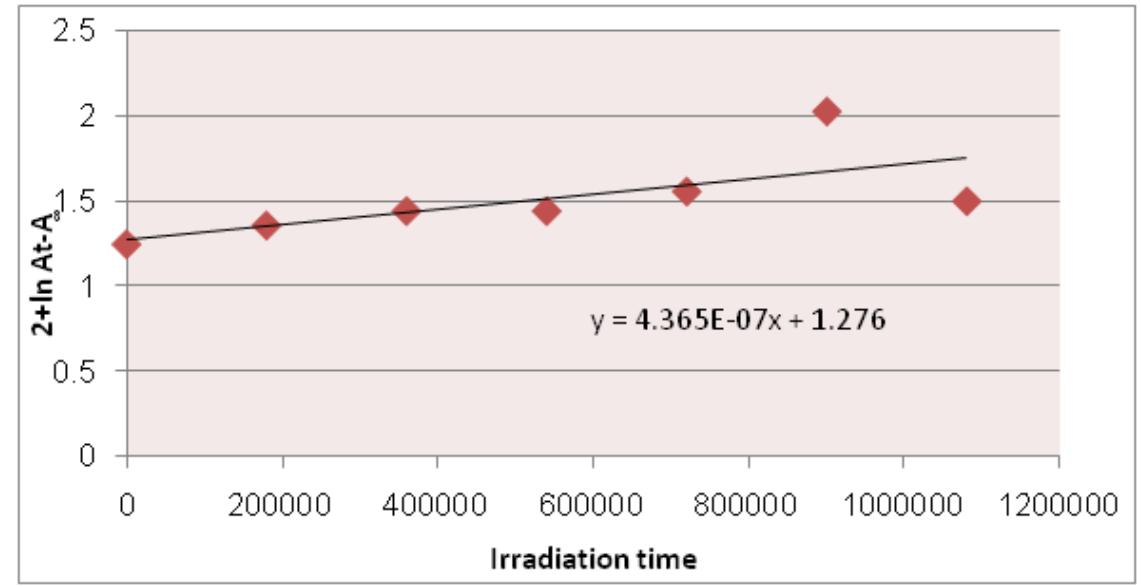

Fig. 2: Variation of natural logarithm of $\ln \left(A_{t}-A_{n}\right)$ with irradiation time of PS (blank) film

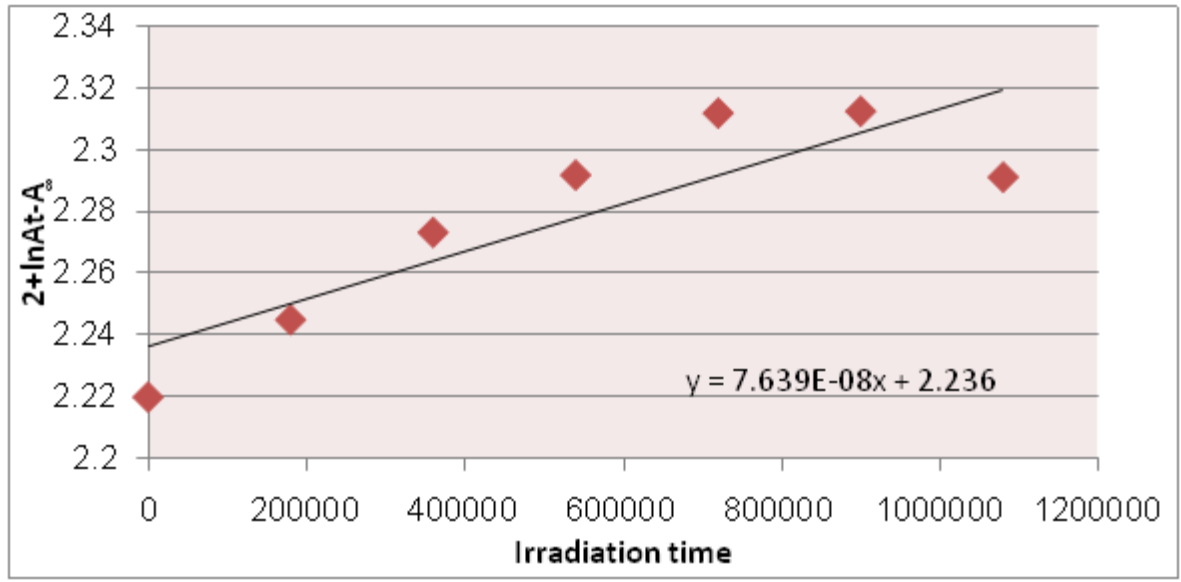

Fig. 3: Variation of natural logarithm of $\ln \left(A_{t}-A_{n}\right)$ with irradiation time of $N i(L)_{2}$ in PS film 
Substitution of a and $(a-x)$ from equation (2.6) in (2.5) gives:

$$
\ln \left(A_{t}-A_{¥}\right)=\ln \left(A_{o}-A_{¥}\right)-K_{d} t
$$

Thus a plot of $\ln \left(A_{t}-A_{¥}\right)$ versus irradiation time $(\mathrm{t})$ gives straight line with a slope equal $\left(\mathrm{K}_{\mathrm{d}}\right)$ which indicates that photodecomposition of the additives is first order.

\section{RESULTS AND DISCUSSION}

Study of the efficiency of prepared Schiff's basses as photostabilizers of PS films by ultraviolet spectroscopy:

Ultraviolet radiations are known to have deleterious effects on most industrial polymers inducing chemical modification and scission of polymer chain, which ultimately lead to an undesirable loss of the mechanical and surface properties of the irradiated material. Photodegradation of PS causes discoloration (yellowing), cross-linking, and chain scission due to oxidation and effect of UV light and heat (Rabek, 1987), (Kiatkamjornwong et al., 1999). UV light induces the production of radicals by oxidation. The prepared complexes were used as photostabilizers to PS films comparing with PS blank. The additives used in this study were chosen to be completely soluble in polymer solvent, (chloroform). It has been notice that the additives used in the present work are photodecomposed during the photolysis. Thus the photo decomposition rate constant $\left(\mathrm{K}_{\mathrm{d}}\right)$ was calculated. The $\mathrm{K}_{\mathrm{d}}$ values were computed using the UV. spectra changes of PS films thickness $401 / 4 \mathrm{~m}$ containing $0.5 \% \mathrm{w} / \mathrm{w}$ from additives. The plot of irradiation time versus In $\left(A_{t}-A Z\right)$, gives straight

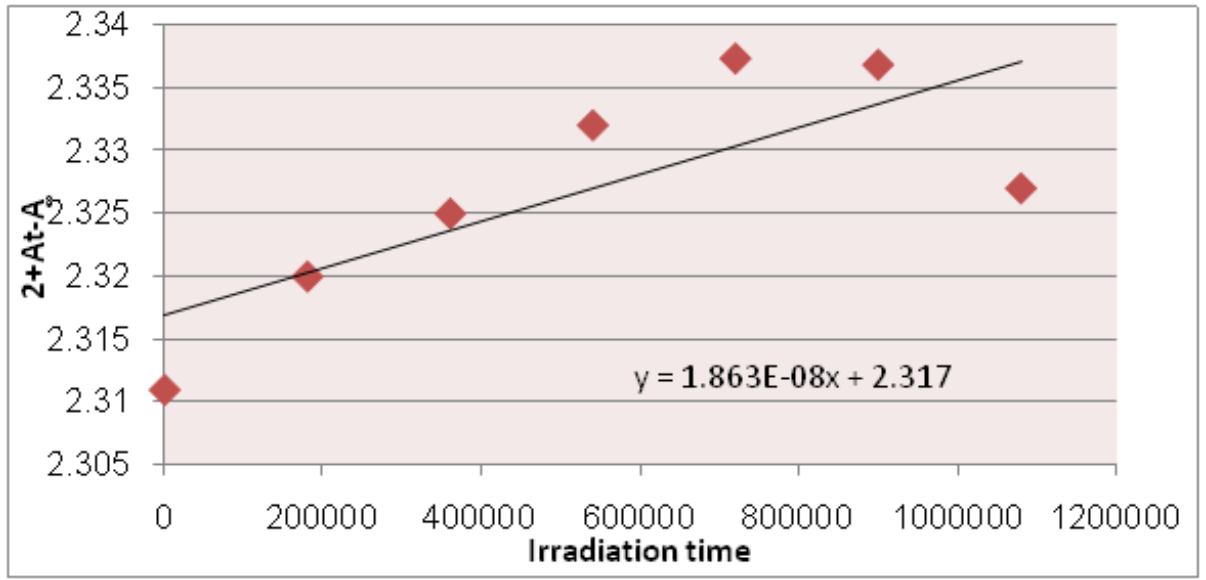

Fig. 4: Variation of natural logarithm of In $\left(A_{t}-A_{n}\right)$ with irradiation time of $C u(L)_{2}$ in PS film

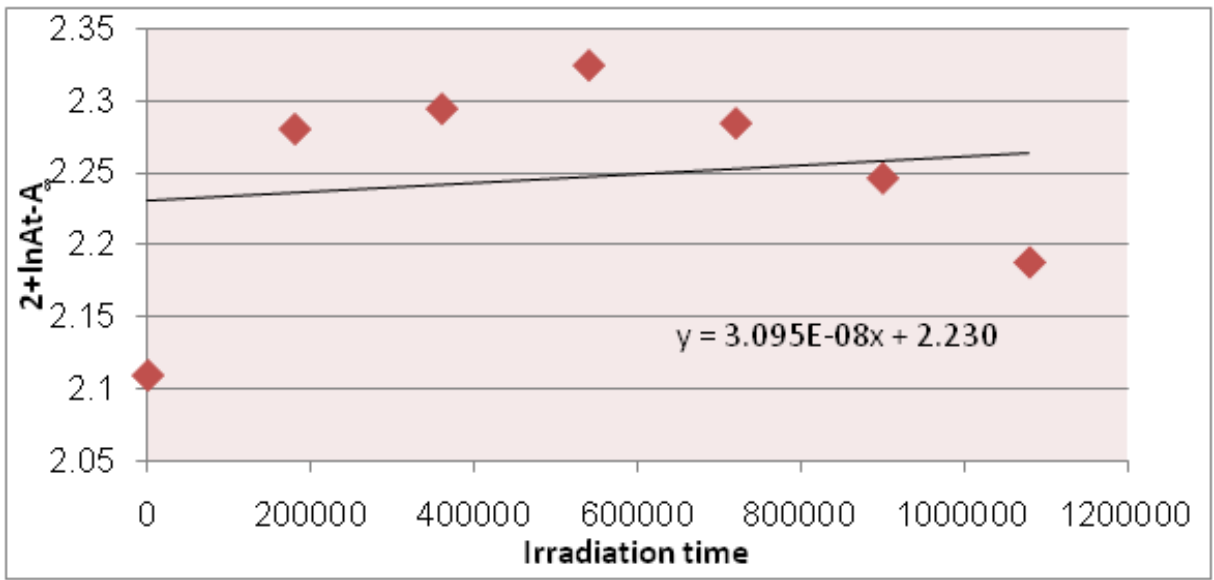

Fig. 5: Variation of natural logarithm of $\ln \left(A_{t}-A_{n}\right)$ with irradiation time of $Z n(L)_{2}$ in PS film 


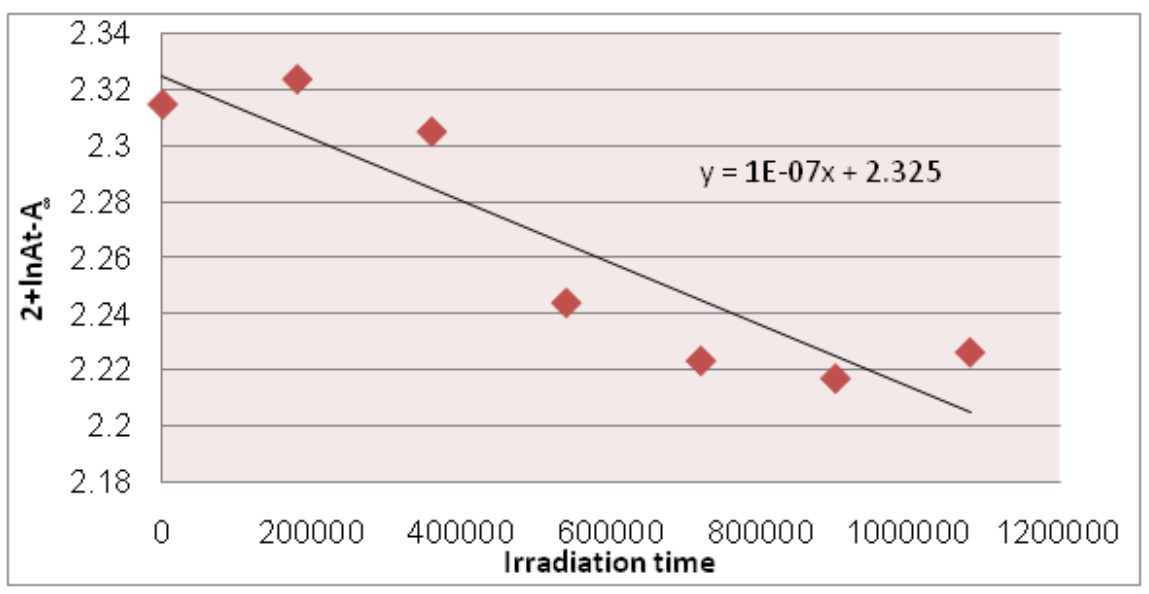

Fig. 6: Variation of natural logarithm of $\ln \left(A_{t}-A_{n}\right)$ with irradiation time of $C d(L)_{2}$ in PS film

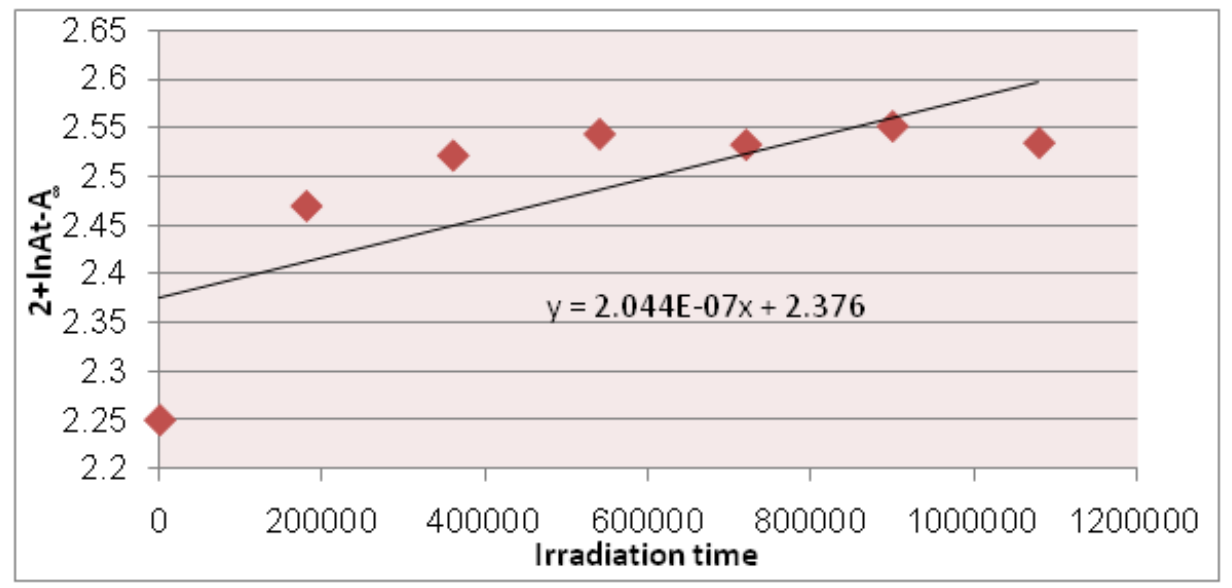

Fig. 7: Variation of natural logarithm of $\ln \left(A_{t}-A_{n}\right)$ with irradiation time of $S n(L)_{2}$ in PS film

Table. 1: Photodecomposition rate constant $\left(K_{d}\right)$ of PS films thickness $(40 \mathrm{~mm})$ containing $0.5 \%$ of additives

\begin{tabular}{ll}
\hline Polymers & $\mathrm{K}_{\mathrm{d}}\left(\mathrm{S}^{-1}\right)$ \\
\hline $\mathrm{PS}$ (blank) & $4.365 \times 10^{-7}$ \\
$\mathrm{PS}+\mathrm{Ni}(\mathrm{L})_{2}$ & $7.639 \times 10^{-8}$ \\
$\mathrm{PS}+\mathrm{Cu}(\mathrm{L})_{2}$ & $2.863 \times 10^{-8}$ \\
$\mathrm{PS}+\mathrm{Zn}(\mathrm{L})_{2}$ & $3.095 \times 10^{-8}$ \\
$\mathrm{PS}+\mathrm{Cd}(\mathrm{L})_{2}$ & $1.000 \times 10^{-7}$ \\
$\mathrm{PS}+\mathrm{Sn}(\mathrm{L})_{2}$ & $2.044 \times 10^{-7}$ \\
\hline
\end{tabular}

line which indicate primarily the first order reaction. The slope equal to the decomposition rate constant $\mathrm{K}_{\mathrm{d}}$. Figure (2),(3),(4),(5),(6) and (7) shows the variation of $\ln \left(A_{t}-A Z\right)$ with irradiation time for all additives in PS films at $»=365 \mathrm{~nm}$.

The values of the first order rate constant of all the modified polymers films $\left(k_{d}\right)$ calculated by the same way and shown in Table (3.9).

The photostabilizers always posses low $K_{d}$ values, which mean that these modified polymers are stable towards UV light. One could notice that $K_{d}$ values are sensitive to the type of additives in PS films, which decrease in the following order:

$\mathrm{Cu}(\mathrm{L})_{2}$

$$
\mathrm{PS}>\mathrm{Sn}(\mathrm{L})_{2}>\mathrm{Cd}(\mathrm{L})_{2}>\mathrm{Ni}(\mathrm{L})_{2}>\mathrm{Zn}(\mathrm{L})_{2}>
$$
and this might point out to increase the photostability of this additives in this term. 


\section{ACKNOWLEDGEMENTS}

The authors thank Al-Nahrain University and Universiti Kebangsaan Malaysia for the funding
(Codes AP-2011 17, DPP-2013-054, UKM-MI-OUP2011, AP-2012-017, and DLP 2013-002).

\section{REFERENCES}

1. Al-Maydama, H., Al-Ansi, T., Jamil, Y. \& Ali, A., Biheterocyclic ligands: Synthesis, characterization and coordinating properties of bis(4-amino-5-mercapto-1,2,4-triazol-3-yl) alkanes with transition metal ions and their thermokinetic and biological studies. ECl. Quim. 2008, 33(3): 29-42,.

2. Cooray, B. \& Scott, G., Polymer Photodegradation: Mechanisms and Experimental Methods. J. Eur. Polym. 1980; 169(16): 177-189.

3. Gugumus, F., Development in Polymer Stabilization-1, (G. Scott, ed.). Applied Science Publishers Ltd. London: 1979; 261272.

4. Haddad, R., Yousif, E. \& Ahmed, A., Synthesis and characterization of transition metal complexes of 4-Amino-5-pyridyl-4H-1,2,4triazole-3-thiol. Springer Plus. 2013; 2: 510516.

5. Kiatkamjornwong, S., Sonsuk, M., Wittayapichet, S., Prasassarakich, P., Vejjanukroh, P., Degradation of styrene-gcassava starch filled polystyrene plastics. Polym. Degrad. Stab. 1999; 66: 323-334.

6. Lawrence, J. \& Weir, N., Photodecomposition of polystyrene on long-wave ultraviolet irradiation: A possible mechanism of initiation of photooxidation. J. Polym. Sci. 2003; 11(1): 105-118.

7. Meenakshi, P., Noorjahan, E., Rajini, R., Venkateswarlu, U. \& Crose S., Mechanical and microstructure studies on the modification of CA film by blending with Polystyrene. Indian Academy of Sciences. 2002; 25(1): 25-29.

8. Mori, F., Koyama, M. \& Oki, Y., Physical Properties ofPolymers Handbook. Angew. Makromol. Chem., 1979; 75: 113-122.

9. Narayana, B. \& Gajendragad, M., Complexes of $\mathrm{Zn}(\mathrm{II}), \mathrm{Pd}(\mathrm{II}), \mathrm{Hg}(\mathrm{II}), \mathrm{Pb}(\mathrm{II}), \mathrm{Cu}(\mathrm{I}), \mathrm{Ag}(\mathrm{I})$, and
$\mathrm{Ti}(\mathrm{I})$ with 4-amino-5-merccapto-3-(otolyloxymethyl)-1,2,4-troazol. Tr. J. of chemistry Tur. J. Chem., 1997; 21:71-76.

10. Rabek, F., Mechanism of Photophysical Process and Photochemical Reaction in polymers. John Wiley and Sons. New York, 1987.

11. Rabek, J. \& Ranby, b., Studies on the photooxidation mechanism of polymers. II. The role of quinones as sensitizers in the photooxidative degradation of polystyrene. J. of Polymer Sci. 2003; 2(2); 295-306.

12. Safy Eldin, M. \& El-laithy A., Photooxidative degradation of polystyrene of cover signals lamp of some automobile, Journal of applied Polymer Science. 1994; 55: 47-54.

13. Yousif, E. \& Haddad, R., Photodegradation and photostabilization of polymers, especially polystyrene: review. Springer Plus. 2013; 2:398-460.

14. Yousif, E., Haddad, R., \& Ahmed, A., Photodegradation and photostabilization of polymers especially polystyrene. Lambert Academic Publishing. Germany (A), 2013.

15. Yousif, E., Hameed, A., Salih, N., Salimon, J. \& Abdullah, BM., New photostabilizers for polystyrene based on 2,3-dihydro-(5mercapto-1,3,4-oxadiazol-2-yl)-phenyl-2(substituted)-1,3,4-oxazepine- 4,7-dione compounds. Springer Plus J., 2013; 1-8.(B)

16. Yousif, E., Salimon, J.\& Salih, N., Improvement of photostabilization of PVC in the presence of thioacitic acidbenzothiazole complexes. The Malaysian J. of Analytical Sciences. 2011; 15(1): 81-92.

17. Yousif, E., Salimon, J. \& Salih, N., New stabilizer for polystyrene based on 2Thioacetic Acid Benzothiazol complexes. J. of Applied Polymer Science. 2012; 125: 19221927. 